\title{
Experimental Models of Spontaneous Ventricular Arrhythmias and of Sudden Cardiac Death
}

\author{
M. ŠTENGL ${ }^{1}$ \\ ${ }^{1}$ Department of Physiology, Faculty of Medicine in Plzeň, Charles University in Prague, Plzeň, \\ Czech Republic
}

Received January 29, 2010

Accepted March 26, 2010

\begin{abstract}
Summary
Sudden cardiac death defined as natural death from cardiac causes occurring within one hour of the onset of acute symptoms is one of the most significant non-injury causes of death in the adult population of industrialised countries. The understanding of the mechanisms leading to sudden cardiac death is so far limited. Recently, a number of experimental animal models with high incidence of sudden cardiac death were developed and are intensively studied to get new insights into the sudden cardiac death mechanisms. In this review the animal models of sudden cardiac death are summarized and their principal properties shortly described.
\end{abstract}

\section{Key words}

Heart • Sudden cardiac death • Experimental animal model

\section{Corresponding author}

M. Štengl, Department of Physiology, Faculty of Medicine in Plzeň, Charles University in Prague, Lidická 1, 30166 Plzeň, Czech Republic. Fax: +420377593 349. E-mail: milan.stengl@lfp.cuni.cz

\section{Sudden cardiac death}

Cardiovascular disease is the most frequent cause of death in the world; in the Czech Republic it accounts for $52 \%$ of all deaths (Institute of Health Information and Statistics of the Czech Republic). One of the most significant non-injury causes of death in the adult population of industrialised countries is sudden cardiac death, defined as natural death from cardiac causes occurring within one hour of the onset of acute symptoms. Sudden cardiac death represents $\sim 10 \%$ of all natural deaths (Kuller et al. 1967) and approximately $2 / 3$ of all sudden non-trauma deaths in the adult population (Thomas et al. 1988). For about $3 / 4$ of those afflicted by sudden cardiac death, coronary artery disease is present and sudden cardiac death can be the first manifestation of this disease. The prevalence of sudden cardiac death is also higher in cardiomyopathy (hypertrophic, dilated, right ventricle). The risk factors for sudden cardiac death therefore correspond to the risk factors for coronary atherosclerosis and include, e.g., increased LDL cholesterol, obesity, hypertension, diabetes and smoking (Priori et al. 2001). Nevertheless, in about five to ten percent of cases, sudden cardiac death occurs with no presence of coronary disease or cardiomyopathy. It is likely that these cases predominantly represent arrhythmogenic syndromes (channelopathies) which increase the risk of ventricular tachyarrhythmia and sudden cardiac death without significant structural changes of the heart (long QT syndrome, Brugada syndrome, catecholaminergic polymorphic ventricular tachycardia) (Priori et al. 2002a, 2002b, 2003). The predominant mechanism of sudden cardiac death is ventricular tachyarrhythmia, particularly ventricular fibrillation (Zipes et al. 2006). The processes that lead to the onset (and maintaining) of ventricular fibrillation, however, remain unexplained. Given the variable initial heart conditions (from a structurally normal heart to cardiac hypertrophy, acute ischemia or cardiac arrest), the processes are likely multifactorial and dynamic. At a given moment in a given person, the combination of one or more trigger events 
(acute ischemia, physical activity, mental stress, ionic changes) with the appropriate myocardial substrate (hypertrophic myocardium, ischemic myocardium, failing myocardium, myocardium with channelopathy) will subsequently lead to the onset of fatal ventricular tachyarrhythmia and sudden cardiac death. Besides changes on the level of cardiac myocytes (electric, contractile and structural remodelling), changes in the cardiac autonomous innervation (neural remodelling) also play a role (Efimov 2003). Detailed understanding of the mechanisms leading to sudden cardiac death is absolutely necessary for developing methods that will allow determining with sufficient reliability which individuals are at significantly high risk of sudden cardiac death. Given the prevalence of sudden cardiac death, which is about 1/1000/year among the European and North American population (Priori et al. 2001, Zipes et al. 2006), whole-population interventions are impossible and the only meaningful strategy appears to be identifying individuals with an increased risk of sudden death and applying individualised preventative measures for these patients. For investigation of mechanisms leading to sudden cardiac death and determination of risk indicators the experimental animal models with high incidence of spontaneous ventricular arrhythmias and of sudden cardiac death are absolutely necessary.

\section{Mouse/rat models}

With the development of transgenic animal technology a huge (and still growing) number of various experimental mouse/rat models appeared. From point of view of cardiac electrophysiology and arrhythmology, however, a substantial limitation of these models must be taken into account: Mouse cardiac electrophysiological characteristics are significantly different from those of human. The duration of mouse cardiac action potential is very short; the plateau phase is not present. The major ionic currents contributing to action potential are different from those in human (for review see Nerbonne 2004). Heart rate of mice is extremely high (resting heart rate of $600 \mathrm{bpm}$ ). Due to these differences, the translation of the results obtained in mouse studies to human physiology and clinic must be very cautious.

\section{Transgenic mouse with long-QT3 syndrome}

The mouse with long-QT3 syndrome (LQT3) was one of the first mouse models of proarrhythmia (Nuyens et al. 2001). Consistent with LQT3 patients, a deletion of amino-acid residues 1505-1507 (KPQ) in the cardiac sodium channel, encoded by SCN5A gene, caused an abnormal prolongation of repolarization associated with fatal ventricular arrhythmias. The inactivation of sodium channel was impaired producing an additional depolarizing current $\mathrm{I}_{\mathrm{NaL}}$ (late sodium current). As an unexpected feature, a paradoxical lengthening of repolarization with early afterdepolarization and triggered arrhythmias in response to sudden heart rate acceleration or premature beats was found. The relevance of this novel arrhythmogenic mechanism for LQT3 patients remains to be determined.

\section{Transgenic mouse with cardiac-restricted knockout of} connexin43

Mice with cardiac-specific loss of connexin43 have normal heart structure (normal left ventricular chamber size and wall thickness) and contractile performance (assessed by echocardiography in 1-monthold mice), however they develop uniformly sudden cardiac death from spontaneous ventricular arrhythmias within 2 months of age (Gutstein et al. 2001). Ventricular conduction velocity was significantly slowed in both transverse (by up to $55 \%$ ) and longitudinal (by $42 \%$ ) directions. The findings clearly document the essential role of gap junctions/connexin43 in the maintenance of electrical stability of the heart.

\section{Transgenic mice with suppression of cardiac potassium} currents

To investigate the contribution of potassium currents to cardiac repolarization and dispersion of repolarization and the role of dispersion of repolarization in promoting arrhythmia, London et al. (2007) engineered mouse models which lack $\mathrm{I}_{\text {to,f }}$ (rapidly activating, rapidly inactivating transient outward potassium current encoded by Kv4.2), $\mathrm{I}_{\mathrm{to}, \mathrm{s}}$ (a more slowly inactivating component of the transient outward current encoded by Kv1.4) or both. Mice that lacked $\mathrm{I}_{\mathrm{to}, \mathrm{f}}$, had action potential and QT-interval prolongation, but no spontaneous arrhythmia. Mice that lacked $\mathrm{I}_{\mathrm{to}, \mathrm{s}}$, had no QT-interval prolongation and no arrhythmia. Mice that lacked both $\mathrm{I}_{\mathrm{to}, \mathrm{f}}$ and $\mathrm{I}_{\mathrm{to}, \mathrm{s}}$, had action potential and QT-interval prolongation, and spontaneous ventricular arrhythmias. Dispersion of repolarization was only increased in mice that lacked both $\mathrm{I}_{\mathrm{to}, \mathrm{f}}$ and $\mathrm{I}_{\mathrm{to}, \mathrm{s}}$. Thus, elimination of repolarizing potassium currents may lead to increased dispersion of repolarization and the dispersion of repolarization appears to be an important determinant of arrhythmia vulnerability. 


\section{Mouse/rat models of cardiomyopathies}

A huge number of mouse/rat models were developed for investigation of pathways involved in pathogenesis of cardiomyopathy. A variety of gene mutations may finally manifest as cardiomyopathy. Hypertrophic cardiomyopathy is typically caused by mutations in genes encoding proteins of the sarcomere. Dilated cardiomyopathy may be related to mutations in genes for proteins of sarcomere, cytoskeleton and nuclear envelope. Arrhythmogenic right ventricular cardiomyopathy is caused mainly by mutations in genes encoding proteins of desmosomes, which are the intercellular junctions linking the cardiomyocytes. From various models of cardiomyopathies available nowadays a number of them are associated with increased susceptibility to arrhythmias and sudden cardiac death. A comprehensive review of current animal models for inherited arrhythmogenic cardiomyopathies was published recently (McCauley and Wehrens 2009).

\section{Rabbit models}

The rabbit ventricular action potentials resemble the human ventricular action potentials much more than those of mouse or rat. The action potential shows the typical positive plateau phase and the duration approaches the values in human. All major ionic currents contributing to human ventricular action potential are present in rabbit ventricular cells, although some quantitative and kinetic differences may be identified. The small size of the rabbit heart (compared to human) may limit some spatial phenomena like transmural heterogeneity of action potentials. Anyway, compared to mouse, the results obtained in rabbit cardiac preparations should be more relevant and easier to translate to the human physiology.

\section{Transgenic rabbit with long-QT syndrome}

Expression of pore mutants of the human genes KCNQ1 and KCNH2 in the rabbit heart produced phenotypes of long-QT1 and long-QT2 syndromes, respectively (Brunner et al. 2008). Analysis of the transgenic rabbits revealed that the prolongation of QT-interval and action potential duration was due to elimination of $\mathrm{I}_{\mathrm{Ks}}$ and $\mathrm{I}_{\mathrm{Kr}}$ currents, respectively. LongQT2 rabbits showed a high incidence of spontaneous sudden cardiac death $(>50 \%$ at 1 year $)$ due to polymorphic ventricular tachycardia. Optical mapping studies revealed increased spatial dispersion of repolarization underlying the re-entrant arrhythmias in long-QT2 rabbits. Interestingly, the elimination of 1 repolarizing current (e.g. $\mathrm{I}_{\mathrm{Kr}}$ ) was associated with downregulation of the other current (e.g. $\mathrm{I}_{\mathrm{Ks}}$ ), in contrast to compensatory upregulation found in mouse long-QT models (Guo et al. 1999, 2000).

\section{Rabbit with chronic atrioventricular block}

Chronic complete atrioventricular block in the rabbit led within several weeks to biventricular hypertrophy, prolongation of QT-interval and action potential duration and spontaneous torsade de pointes arrhythmias (Tsuji et al. 2002). The prolongation of repolarization was due to downregulation of potassium repolarizing currents $\mathrm{I}_{\mathrm{Ks}}$ and $\mathrm{I}_{\mathrm{Kr}}$. All noneuthanized rabbits died suddenly between 0 and 38 days of escape rhythm. The linear relationship between the date of first torsade de pointes arrhythmia event and survival period suggests the arrhythmic mechanism of death, however, at least in some rabbits the heart failure cannot be excluded.

\section{Hypercholesterolemic rabbit}

Hypercholesterolemic diet fed for 12 weeks induced a pronounced hypercholesterolemia that was associated with electrophysiological and neural remodeling of the heart (Liu et al. 2003). Only minimal coronary atherosclerosis was observed in epicardial coronary arteries and there was no evidence of myocardial infarction. The electrophysiological remodeling was characterized by prolongation of QT interval and action potential duration, increased QT dispersion and heterogeneity of repolarization and higher calcium current density. The neural remodeling involved significant nerve sprouting and sympathetic hyperinnervation. Cardiac hypertrophy was also present in hypercholesterolemic rabbits. Together the electrophysiological and neural remodelings resulted in increased vulnerability to ventricular fibrillation.

\section{Dog models}

From the point of view of cardiac electrophysiology, the canine heart appears to be the most relevant model for studying and translating mechanisms of arrhythmias. The major ionic currents correspond well to those in human myocardium. Duration and shape of action potential and heart rate approach the human values. The size of the heart is sufficient to study conveniently the spatial phenomena involved in 
arrhythmogenesis like heterogeneity of repolarization or spread of excitation.

\section{Dog with chronic atrioventricular block}

The bradycardia-induced volume overload due to the chronic atrioventricular block results within several weeks in complex structural, contractile and electrophysiological remodelling. Cardiac hypertrophy was observed on both organ and cellular levels (Volders et al. 1998, Vos et al. 1998). Contractile remodelling compensates the cardiac output and it is associated with enhanced calcium release (de Groot et al. 2000, Sipido et al. 2000). Electrophysiological remodelling comprises downregulation of potassium currents $\mathrm{I}_{\mathrm{Ks}}$ and $\mathrm{I}_{\mathrm{Kr}}$ (Volders et al. 1999) and upregulation of sodium-calcium exchanger (Sipido et al. 2000). All these alterations predispose to torsade de pointes arrhythmia and sudden cardiac death (Vos et al. 1995, van Opstal et al. 2001).

German shepherd dogs with inherited ventricular arrhythmia and sudden cardiac death

A colony of German shepherd dogs that exhibit inherited ventricular arrhythmia and sudden arrhythmic death was established (Moise et al. 1997). The incidence of arrhythmias increased with age (between 7 and 28 weeks of age) and was related to age-dependent reduction in sinus rate. Abnormal heterogeneous cardiac sympathetic innervation, decreased density of potassium current $\mathrm{I}_{\text {to }}$, abnormal calcium handling and spatial heterogeneity in ventricular $\mathrm{I}_{\mathrm{Kr}}$ expression probably contribute to the arrhythmic phenotype of these dogs (Dae et al. 1997, Freeman et al. 1997, Steinberg et al. 2002, Obreztchikova et al. 2003).

Boxer dogs with arrhythmogenic right ventricular cardiomyopathy

Arrhythmogenic right ventricular

cardiomyopathy is an inherited cardiac disease associated with substantial cardiovascular morbidity and sudden death in young people (Thiene et al. 1988). Causative mutations were identified in genes encoding desmosomal proteins (Basso et al. 2009). A spontaneous, genetically transmitted model of arrhythmogenic right ventricular cardiomyopathy, closely resembling the human disease, was described in boxer dogs (Basso et al. 2004). Clinical events included sudden death, ventricular arrhythmias of suspected right ventricular origin, syncope and heart failure. Severe right ventricular myocyte loss with replacement by fatty or fibrofatty tissue was present. The cardiomyopathy in the model was shown to be associated with a substantial loss of gap junction plaques as well as with remodeling of other intercalated disc structures (Oxford et al. 2007). Calstabin2 deficiency associated with a significantly increased open probability of single sarcoplasmic reticulum release channels was also identified and suggested as a potential mechanism for calcium leak-induced ventricular arrhythmias in these dogs (Oyama et al. 2008).

\section{Pig models}

Similar to dog, the pig heart also represent a good model highly relevant for human cardiac electrophysiology, in many aspects similar to human heart. A significant electrophysiological difference is the lack of potassium current $\mathrm{I}_{\text {to }}$ (Li et al. 2003, Schultz et al. 2007) that is present in human as well as in canine myocardium.

\section{Pig with hibernating myocardium}

Pigs with hibernating myocardium arising from a chronic coronary artery occlusion have a high rate of sudden cardiac death, cumulative mortality attributable to sudden cardiac death being $49 \%$ after 5 months (Canty et al. 2004). Ventricular fibrillation was documented as the arrhythmic mechanism of death. Action potential prolongation in hibernating myocytes was documented (Bito et al. 2004) and the increased electrical heterogeneity of the myocardium could contribute to the arrhythmogenic substrate. Spatial inhomogeneity of sympathetic innervation in hibernating myocardium may be another factor contributing to lethal arrhythmias (Luisi et al. 2002).

\section{Conclusions}

A significant number of animal models with high incidences of lethal ventricular arrhythmias are available nowadays for studying the mechanisms of sudden cardiac death. The wide range of models documents the variety of sudden cardiac death mechanisms when a particular combination of a trigger event with a myocardial substrate in a given individual results in sudden death. A detailed understanding of the mechanisms leading to sudden cardiac death is absolutely necessary for development of diagnostic, preventive and therapeutic strategies that will in the end reduce the risk of sudden cardiac death in the population. Obviously the 
translation of experimental results obtained in animal models to patient will be an ambitious and difficult task. Interpretation of various sudden death mechanisms occurring in the models will be always complicated by species differences. In this respect the comparative (patho)physiology must be taken into account and complement the translational efforts.

\section{Conflict of Interest}

There is no conflict of interest.

\section{Acknowledgements}

The work was supported by the Research Project MSM 0021620819, Replacement of and support to some vital organs, from the Ministry of Education, Czech Republic.

\section{References}

BASSO C, CORRADO D, MARCUS FI, NAVA A, THIENE G: Arrhythmogenic right ventricular cardiomyopathy. Lancet 373: 1289-1300, 2009.

BASSO C, FOX PR, MEURS KM, TOWBIN JA, SPIER AW, CALABRESE F, MARON BJ, THIENE G: Arrhythmogenic right ventricular cardiomyopathy causing sudden cardiac death in boxer dogs: a new animal model of human disease. Circulation 109: 1180-1185, 2004.

BITO V, HEINZEL FR, WEIDEMANN F, DOMMKE C, VAN DER VELDEN J, VERBEKEN E, CLAUS P, BIJNENS B, DE SCHEERDER I, STIENEN GJ, SUTHERLAND GR, SIPIDO KR: Cellular mechanisms of contractile dysfunction in hibernating myocardium. Circ Res 94: 794-801, 2004.

BRUNNER M, PENG X, LIU GX, REN XQ, ZIV O, CHOI BR, MATHUR R, HAJJIRI M, ODENING KE, STEINBERG E, FOLCO EJ, PRINGA E, CENTRACCHIO J, MACHARZINA RR, DONAHAY T, SCHOFIELD L, RANA N, KIRK M, MITCHELL GF, POPPAS A, ZEHENDER M, KOREN G: Mechanisms of cardiac arrhythmias and sudden death in transgenic rabbits with long QT syndrome. J Clin Invest 118: 2246$2259,2008$.

CANTY JM JR, SUZUKI G, BANAS MD, VERHEYEN F, BORGERS M, FALLAVOLLITA JA: Hibernating myocardium: chronically adapted to ischemia but vulnerable to sudden death. Circ Res 94: 1142-1149, 2004.

DAE MW, LEE RJ, URSELL PC, CHIN MC, STILLSON CA, MOISE NS: Heterogeneous sympathetic innervation in German shepherd dogs with inherited ventricular arrhythmia and sudden cardiac death. Circulation 96: 1337$1342,1997$.

DE GROOT SH, SCHOENMAKERS M, MOLENSCHOT MM, LEUNISSEN JD, WELLENS HJ, VOS MA: Contractile adaptations preserving cardiac output predispose the hypertrophied canine heart to delayed afterdepolarization-dependent ventricular arrhythmias. Circulation 102: 2145-2151, 2000.

EFIMOV IR: Fibrillation or neurillation. Back to the future in our concepts of sudden cardiac death? Circ Res 92: $1062-$ 1064, 2003.

FREEMAN LC, PACIORETTY LM, MOISE NS, KASS RS, GILMOUR RF JR: Decreased density of Ito in left ventricular myocytes from German shepherd dogs with inherited arrhythmias. J Cardiovasc Electrophysiol 8: 872-883, 1997.

GUO W, LI H, LONDON B, NERBONNE JM: Functional consequences of elimination of i(to,f) and i(to,s): early afterdepolarizations, atrioventricular block, and ventricular arrhythmias in mice lacking Kv1.4 and expressing a dominant-negative Kv4 alpha subunit. Circ Res 87: 73-79, 2000.

GUO W, XU H, LONDON B, NERBONNE JM: Molecular basis of transient outward K+ current diversity in mouse ventricular myocytes. $J$ Physiol Lond 521: 587-599, 1999.

GUTSTEIN DE, MORLEY GE, TAMADDON H, VAIDYA D, SCHNEIDER MD, CHEN J, CHIEN KR, STUHLMANN H, FISHMAN GI: Conduction slowing and sudden arrhythmic death in mice with cardiacrestricted inactivation of connexin43. Circ Res 88: 333-339, 2001.

KULLER L, LILIENFELD A, FISHER R: An epidemiological study of sudden and unexpected deaths in adults. Medicine (Baltimore) 46: 341-361, 1967.

LI GR, DU XL, SIOW YL, O K, TSE HF, LAU CP: Calcium-activated transient outward chloride current and phase 1 repolarization of swine ventricular action potential. Cardiovasc Res 58: 89-98, 2003. 
LIU YB, WU CC, LU LS, SU MJ, LIN CW, LIN SF, CHEN LS, FISHBEIN MC, CHEN PS, LEE YT: Sympathetic nerve sprouting, electrical remodeling, and increased vulnerability to ventricular fibrillation in hypercholesterolemic rabbits. Circ Res 92: 1145-1152, 2003.

LONDON B, BAKER LC, PETKOVA-KIROVA P, NERBONNE JM, CHOI BR, SALAMA G: Dispersion of repolarization and refractoriness are determinants of arrhythmia phenotype in transgenic mice with long QT. J Physiol Lond 578: 115-129, 2007.

LUISI AJ JR, FALLAVOLLITA JA, SUZUKI G, CANTY JM JR: Spatial inhomogeneity of sympathetic nerve function in hibernating myocardium. Circulation 106: 779-781, 2002.

MCCAULEY MD, WEHRENS XH: Animal models of arrhythmogenic cardiomyopathy. Dis Model Mech 2: 563-570, 2009.

MOISE NS, RICCIO ML, KORNREICH B, FLAHIVE WJ JR, GILMOUR RF JR: Age dependence of the development of ventricular arrhythmias in a canine model of sudden cardiac death. Cardiovasc Res 34: 483492, 1997.

NERBONNE JM: Studying cardiac arrhythmias in the mouse--a reasonable model for probing mechanisms? Trends Cardiovasc Med 14: 83-93, 2004.

NUYENS D, STENGL M, DUGARMAA S, ROSSENBACKER T, COMPERNOLLE V, RUDY Y, SMITS JF, FLAMENG W, CLANCY CE, MOONS L, VOS MA, DEWERCHIN M, BENNDORF K, COLLEN D, CARMELIET E, CARMELIET P: Abrupt rate accelerations or premature beats cause life-threatening arrhythmias in mice with long-QT3 syndrome. Nat Med 7: 1021-1027, 2001.

OBREZTCHIKOVA MN, SOSUNOV EA, ANYUKHOVSKY EP, MOISE NS, ROBINSON RB, ROSEN MR: Heterogeneous ventricular repolarization provides a substrate for arrhythmias in a German shepherd model of spontaneous arrhythmic death. Circulation 108: 1389-1394, 2003.

OXFORD EM, EVERITT M, COOMBS W, FOX PR, KRAUS M, GELZER AR, SAFFITZ J, TAFFET SM, MOISE NS, DELMAR M: Molecular composition of the intercalated disc in a spontaneous canine animal model of arrhythmogenic right ventricular dysplasia/cardiomyopathy. Heart Rhythm 4: 1196-1205, 2007.

OYAMA MA, REIKEN S, LEHNART SE, CHITTUR SV, MEURS KM, STERN J, MARKS AR: Arrhythmogenic right ventricular cardiomyopathy in Boxer dogs is associated with calstabin2 deficiency. $J$ Vet Cardiol 10: $1-10,2008$.

PRIORI SG, ALIOT E, BLOMSTROM-LUNDQVIST C, BOSSAERT L, BREITHARDT G, BRUGADA P, CAMM AJ, CAPPATO R, COBBE SM, DI MARIO C, MARON BJ, MCKENNA WJ, PEDERSEN AK, RAVENS U, SCHWARTZ PJ, TRUSZ-GLUZA M, VARDAS P, WELLENS HJ, ZIPES DP: Task Force on Sudden Cardiac Death of the European Society of Cardiology. Eur Heart J 22: 1374-1450, 2001.

PRIORI SG, NAPOLITANO C, GASPARINI M, PAPPONE C, DELlA BELlA P, GIORDANO U, BLOISE R, GIUSTETTO C, DE NARDIS R, GRILLO M, RONCHETTI E, FAGGIANO G, NASTOLI J: Natural history of Brugada syndrome: insights for risk stratification and management. Circulation 105: 1342-1347, $2002 \mathrm{a}$.

PRIORI SG, NAPOLITANO C, MEMMI M, COLOMBI B, DRAGO F, GASPARINI M, DESIMONE L, COLTORTI F, BLOISE R, KEEGAN R, CRUZFILHO FE, VIGNATI G, BENATAR A, DELOGU A: Clinical and molecular characterization of patients with catecholaminergic polymorphic ventricular tachycardia. Circulation 106: 69-74, 2002b.

PRIORI SG, SCHWARTZ PJ, NAPOLITANO C, BLOISE R, RONCHETTI E, GRILLO M, VICENTINI A, SPAZZOLINI C, NASTOLI J, BOTTELLI G, FOLLI R, CAPPELLETTI D: Risk stratification in the long-QT syndrome. N Engl J Med 348: 1866-1874, 2003.

SCHULTZ JH, VOLK T, BASSALAY P, HENNINGS JC, HUBNER CA, EHMKE H: Molecular and functional characterization of Kv4.2 and KChIP2 expressed in the porcine left ventricle. Pflugers Arch 454: 195-207, 2007.

SIPIDO KR, VOLDERS PG, DE GROOT SH, VERDONCK F, VAN DE WERF F, WELLENS HJ, VOS MA: Enhanced $\mathrm{Ca}(2+)$ release and $\mathrm{Na} / \mathrm{Ca}$ exchange activity in hypertrophied canine ventricular myocytes: potential link between contractile adaptation and arrhythmogenesis. Circulation 102: 2137-2144, 2000. 
STEINBERG SF, ALCOTT S, PAK E, HU D, PROTAS L, MOISE NS, ROBINSON RB, ROSEN MR: beta(1)Receptors increase cAMP and induce abnormal $\mathrm{Ca}(\mathrm{i})$ cycling in the German shepherd sudden death model. $\mathrm{Am}$ J Physiol 282: H1181-H1188, 2002.

THIENE G, NAVA A, CORRADO D, ROSSI L, PENNELLI N: Right ventricular cardiomyopathy and sudden death in young people. $N$ Engl J Med 318: 129-133, 1988.

THOMAS AC, KNAPMAN PA, KRIKLER DM, DAVIES MJ: Community study of the causes of 'natural' sudden death. Br Med J 297: 1453-1456, 1988.

TSUJI Y, OPTHOF T, YASUKI K, INDEN Y, TAKEMURA H, NIWA N, LU Z, LEE JK, HONJO H, KAMIYA K, KODAMA I: Ionic mechanisms of acquired QT prolongation and torsades de pointes in rabbits with chronic complete atrioventricular block. Circulation 106: 2012-2018, 2002.

VAN OPSTAL JM, VERDUYN SC, LEUNISSEN HD, DE GROOT SH, WELLENS HJ, VOS MA: Electrophysiological parameters indicative of sudden cardiac death in the dog with chronic complete AVblock. Cardiovasc Res 50: 354-361, 2001.

VOLDERS PG, SIPIDO KR, VOS MA, KULCSAR A, VERDUYN SC, WELLENS HJ: Cellular basis of biventricular hypertrophy and arrhythmogenesis in dogs with chronic complete atrioventricular block and acquired torsade de pointes. Circulation 98: 1136-1147, 1998.

VOLDERS PG, SIPIDO KR, VOS MA, SPATJENS RL, LEUNISSEN JD, CARMELIET E, WELLENS HJ: Downregulation of delayed rectifier $\mathrm{K}(+)$ currents in dogs with chronic complete atrioventricular block and acquired torsades de pointes. Circulation 100: 2455-2461, 1999.

VOS MA, DE GROOT SH, VERDUYN SC, VAN DER ZANDE J, LEUNISSEN HD, CLEUTJENS JP, VAN BILSEN M, DAEMEN MJ, SCHREUDER JJ, ALLESSIE MA, WELLENS HJ: Enhanced susceptibility for acquired torsade de pointes arrhythmias in the dog with chronic, complete AV block is related to cardiac hypertrophy and electrical remodeling. Circulation 98: 1125-1135, 1998.

VOS MA, VERDUYN SC, GORGELS AP, LIPCSEI GC, WELLENS HJ: Reproducible induction of early afterdepolarizations and torsade de pointes arrhythmias by d-sotalol and pacing in dogs with chronic atrioventricular block. Circulation 91: 864-872, 1995.

ZIPES DP, CAMM AJ, BORGGREFE M, BUXTON AE, CHAITMAN B, FROMER M, GREGORATOS G, KLEIN G, MOSS AJ, MYERBURG RJ, PRIORI SG, QUINONES MA, RODEN DM, SILKA MJ, TRACY C, SMITH SC JR, JACOBS AK, ADAMS CD, ANTMAN EM, ANDERSON JL, HUNT SA, HALPERIN JL, NISHIMURA R, ORNATO JP, PAGE RL, RIEGEL B, PRIORI SG, BLANC JJ, BUDAJ A, CAMM AJ, DEAN V, DECKERS JW, DESPRES C, DICKSTEIN K, LEKAKIS J, MCGREGOR K, METRA M, MORAIS J, OSTERSPEY A, TAMARGO JL, ZAMORANO JL; American College of Cardiology; American Heart Association Task Force; European Society of Cardiology Committee for Practice Guidelines; European Heart Rhythm Association; Heart Rhythm Society: ACC/AHA/ESC 2006 guidelines for management of patients with ventricular arrhythmias and the prevention of sudden cardiac death: a report of the American College of Cardiology/American Heart Association Task Force and the European Society of Cardiology Committee for Practice Guidelines (Writing Committee to Develop Guidelines for Management of Patients With Ventricular Arrhythmias and the Prevention of Sudden Cardiac Death). J Am Coll Cardiol 48: e247-e346, 2006. 